This PDF is a selection from an out-of-print volume from the National Bureau of Economic Research

Volume Title: Anticipations and Purchases: An Analysis of Consumer Behavior

Volume Author/Editor: F. Thomas Juster

Volume Publisher: Princeton University Press

Volume ISBN: 0-87014-079-5

Volume URL: http://www.nber.org/books/just64-1

Publication Date: 1964

Chapter Title: The Influence of Attitudes and Expectations on Purchases

Chapter Author: F. Thomas Juster

Chapter URL: http://www.nber.org/chapters/c1034

Chapter pages in book: ( $140-165)$ 


\section{The Influence of Attitudes and Expectations on Purchases}

\section{Introduction}

A MAjOR part of the existing research using consumer survey data has been concerned with relating attitudes and expectations to purchase behavior, both in time series and in cross sections. It is here that one finds the sharpest difference of opinion among researchers, both as to the interpretation of empirical results and the related question of usefulness in prediction. ${ }^{1}$

\section{PREVAILING HYPOTHESES}

One view is that consumer attitudes (thought of as generalized feelings of well-being reflecting relative optimism or pessimism) are fundamental determinants of spending and saving behavior and that both expectations (judgments about the course of events external to the household) and intentions (judgments about events internal to the household) are basically attitudes carrying a time dimension. Under this interpretation an appropriate measure of consumer sentiment blends all three kinds of variables in the same way as the characterization of a voter as prospectively Democratic or Republican combines his opinions on philosophical questions, his actual voting record in the past, his economic self-interest as reflected by income status, etc.

1 On the one side are the works of Katona and Mueller: George Katona and Eva Mueller, Consumer Attitudes and Demand, 1950-1952, Ann Arbor, Michigan University Survey Research Center, n.d., pp. 51-61; Katona and Mueller, Consumer Expectations, 1953-1956, Ann Arbor, Michigan University Survey Research Center, n.d.; Katona, "Business Expectations in the Framework of Psychological Economics," Expectations, Uncertainty, and Business Behavior, ed. M. J. Bowman, Ann Arbor, Michigan University Survey Research Center, 1958; Mueller, "Effects of Consumer Attitudes on Purchases," American Economic Review, December 1957; Mueller, "Consumer Attitudes-Their Influence and Forecasting Value," The Quality and Economic Significance of Anticipations Data, Princeton for NBER, 1960; and, most recently, Katona, The Powerful Consumer, New York, McGraw-Hill, 1960. Compare the foregoing with James Tobin, "On the Predictive Value of Consumer Intentions and Attitudes," in Review of Economics and Statistics, February 1959; Arthur Okun, "The Value of Anticipations Data in Forecasting National Product," in Anticipations Data; Reports of Federal Reserve Consultant Committees on Economic Statistics, Joint Committee on the Economic Report, 84th Cong., 1st sess., 1955; F. Thomas Juster, Consumer Expectations, Plans, and Purchases: A Progress Report, Occasional Paper 70, New York, NBER, 1959; Juster, "Prediction and Consumer Buying Intentions," American Economic Review, May 1960; and Juster, "The Predictive Value of Consumers Union Spending-Intentions Data," in Anticipations Data. See also Peter De Janosi, "Factors Influencing the Demand for New Automobiles," Journal of Marketing, April 1959; Lawrence R. Klein and John B. Lansing, "Decision to Purchase Consumer Durable Goods," Journal of Marketing, October 1955; and Lansing and Stephen B. Withey, "Consumer Anticipations: Their Use in Forecasting Consumer Behavior," Short-Term Economic Forecasting, Princeton for NBER, 1955. 
Thus any factor reflecting greater (lesser) optimism will tend to increase (decrease) an individual's optimism index. Holding other attitudes constant, households that report buying intentions or expect increased incomes, ceteris paribus, will have higher index scores and should purchase more than if they reported no buying intentions or expected decreased incomes. Similarly, households with the same expectations and intentions but feeling "better off than last year" will have higher scores than those feeling "worse off," and will make more purchases. In a previous publication I have labeled this viewpoint the "additivity" hypothesis, on the grounds that its proponents argue that any attitude, expectation, or intention reflecting optimism will, ceteris paribus, result in a more favorable disposition towards durable goods purchases, hence be associated with a greater amount of purchases. ${ }^{2}$

An alternative viewpoint is that attitudes, expectations, and intentions should be taken at face value. That is to say, expectations reflect the household's judgment about the future course of events external to the household; intentions, on the other hand, reflect tentative plans to undertake specified actions in the light of these judgments. Attitudes influence both expectations and the relation between expectations and intentions. In this view, purchases (actions) are directly related to (or predicted by) intentions, modified by the incidence of unforeseen developments. I have previously labeled this viewpoint the "contingent-action" hypothesis.

Both of these views relate to the interpretation of responses to survey questions about attitudes, expectations, or intentions. Proponents of both views would agree that these responses are more than a simple extrapolation of the respondent's experience. For if buying intentions or expectations could themselves be predicted from the underlying "real" factors-data on stocks of goods, income, income change, occupation, etc.-measurement of consumer anticipations would be unnecessary. Indeed, many economists regard anticipatory variables as essentially epiphenomena, in that they contain no useful information over and above that provided by knowledge of the household's real situation-its level and rate of change in income, demographic composition, and so forth. However, these economists would probably agree that the availability and timeliness of anticipatory data may well make them of considerable

${ }^{2}$ See Consumer Expectations and "Prediction and Consumer Buying Intentions." The terminology is not intended to convey the impression that any or all possible measures of sentiment carry equal weight or that none interact with others; it is designed to indicate that all measures of consumer sentiment that reflect optimism increase index scores and, hence, are associated with higher rates of purchase, while all measures that reflect pessimism have the reverse effect. 
value in forecasting, even though they may be of no help in understanding or explaining behavior.

The test of these alternative viewpoints is clearly their ability to predict empirically observable phenomena. Appropriate tests are neither simple to construct nor straightforward in interpretation. Take the relation between expected change in income, actual change in income, intentions to buy durables, and actual purchases of durables. The additivity hypothesis predicts that expected change in income will be positively associated with purchases, holding buying intentions and actual income change constant, since the larger the expected income increase the more optimistic the household; hence, the greater the amount of purchases. On the other hand, the contingent-action hypothesis predicts a negative association between expected change in income and purchases, holding intentions and actual income change constant; the larger the expected income increase the less agreeably surprised the household and, hence, the smaller the amount of purchases relative to buying intentions. The third possibility is that no association exists between expected income change and purchases, holding actual income change and past income changes constant, because expected change is nothing more than some kind of weighted average of past changes.

\section{EXISTING EVIDENCE}

These hypotheses can be tested with data from the CU surveys. The relevant test indicates no statistically significant association between $\Delta \hat{Y}$ (expected change in income) and $P$ (purchases of durable goods), holding $\hat{P}$ (buying intentions) and $\Delta Y$ (actual change in income) constant. This conclusion may be correct; but it is quite possible that the observed relation is not significant because the actual relation is more complicated. For example, it is doubtful whether a single-valued estimate of expected change in income is an adequate measure of income expectations. If the structure of such expectations is best described by a probability distribution of the possible outcomes, both the mean and the dispersion of the distribution are surely relevant. A single-valued response is presumably to be interpreted as an estimate of the mean; but we obviously cannot be sure of this. Further, no good measure of dispersion is available. ${ }^{3}$ As a consequence, the difference between actual change in income and my

${ }^{8}$ The basic data contain an estimate of the range of income changes regarded as "at all likely" by the respondent, but this estimate is not available for the time period on which I have concentrated in this monograph. 
single-valued measure of expected change may not be an accurate and unbiased measure of income surprise; and if it is not, the data cannot discriminate among the alternative hypotheses.

Previous investigations into the relation between durable goods purchases and anticipatory variables have generally provided support for the proposition that at least some anticipatory variables are associated with purchases. In particular, buying intentions have always shown a strong statistical relation to purchases in reinterview studies. On the other hand, a relatively weak or nil association has generally been found between attitudes or expectations and purchases. ${ }^{4}$ Tobin's results showed no significant net association between purchases and a number of variables representing attitudes and expectations; buying intentions were significantly related to purchases-actually, to the ratio of durables' purchases to income. A study of the attitude index constructed by Katona and Mueller showed a positive relation between attitudes and purchases net of intentions, income, and age for the second half of 1954, but no significant relation in the first half of $1955 . .^{5}$ In an earlier multivariate study, using dichotomous variables for purchases and intentions to buy, Klein and Lansing could find no important behavioral association between the attitude-expectation variables and purchases; buying intentions, as is customarily the case, were significantly related to purchases. In another earlier study, Lansing and Withey found significant associations between various attitudes or expectations and purchases, but the empirical tests generally involved little netting out of the effects of other variables. Lansing and Withey also found that the difference between expected and actual income change (income surprise) was significantly related to purchases of automobiles, net of intentions to buy.

4 The findings discussed here relate entirely to studies of behavioral differences among a cross section of households. Studies of time series relationships between purchases of durables and expectational variables have been based on relatively few observations; more important for my purposes, the time series studies have not generally attempted to test anticipatory variables net of a sophisticated (objective) model, largely because of the limited number of observations.

The available time series results are relatively more favorable to the hypothesis that attitudes and expectations, as distinct from intentions to buy, are related to purchase behavior. Both intentions $(\hat{P})$ and an index of attitudes $(A)$ show significant relations to purchases in some of these studies. Depending on the time period and the particular choice of variables, it has been found that $P$ is more important than $A$ or vice versa (see Okun; and Mueller, "Consumer Attitudes-Their Influence and Forecasting Value").

5 Mueller, "Effects of Consumer Attitudes on Purchases." In this study both purchases and intentions are modified yes-no constructs rather than dollar amounts, which may tend to weaken all the relationships somewhat. 


\section{SOME EXPLORATORY HYPOTHESES AND INVESTIGATIONS}

In my judgment, existing studies of cross-section data have failed to provide convincing evidence in support of any of the hypotheses described above. On the whole, I read the evidence as suggesting that both attitudes and expectations are essentially unrelated to purchase behavior, while buying intentions are strongly related. It is also possible, however, that these studies have failed to uncover relationships that really exist. Research on these problems has been handicapped to some degree by the relatively small sample sizes available. It is true that six or seven hundred cases are ample for multivariate analysis involving a large number of explanatory factors. But this sample size becomes less satisfactory if some of the variables are important for the young but not for the old, or for households with buying intentions but not for nonintenders, or if combinations of extreme expectations or attitudes are much more important than moderate ones, etc.

On a priori grounds, there is some reason to suppose that the influence of anticipatory variables on purchase behavior is not the same for all subgroups in the population, that the effect of expectations and attitudes is not independent of buying intentions or other attitudes and expectations, and so on. My object in the next two chapters is to explore some of these possibilities at greater length. In the balance of this chapter I analyze the interrelationships among a number of measures bearing on attitudes or expectations, aggregate buying intentions, and aggregate purchases of durable goods. In the next chapter I summarize the results of an extensive multivariate regression analysis.

\section{Purchases and Expectations}

My first concern is with the relation between purchases and a cluster of variables that may be construed as either attitudes or expectations. The relation between purchases and an index of attitudes has been examined in a number of publications by Katona and Mueller. ${ }^{6}$ The component parts of their attitude index have included variables such as expected and past change in financial well being, expectations about general business conditions, opinions about market conditions for durables (good-bad time to buy durables), expectations about price changes plus an evaluation of whether these changes are "to the good" or "to the bad," and buying intentions for durable goods. The index in their cross-section tests is

- For example, see Consumer Attitudes and Demand, pp. 51-61; and Consumer Expectations, p. 10. 
essentially a scale of unweighted scores obtained from a trichotomous distribution of respondents by each of the component variables. ${ }^{7}$ That is to say, respondents are assigned scores of 2,1 , or 0 , depending on whether they expect to be "better off," "the same," or "worse off" in the future. If six such questions are included in the attitude index, scores may range from 12 , corresponding to the maximum degree of optimism, to zero, the maximum degree of pessimism.

Two kinds of problems are involved in the construction of such indexes. First, at face value, some of the components are statements of expectations, i.e., they represent judgments about future events that may or may not happen. The relation between optimistic expectations and purchases may or may not involve a positive association, since, as pointed out above, the net correlation between the two may depend on the difference between expectations and outcomes. If so, optimistic expectations cannot be assigned a score until the corresponding outcome is known, although on the average the appropriate score for a household with optimistic expectations would be lower than that for a household with pessimistic expectations if buying intentions are held constant. On the other hand, statements that seem to represent judgments about future events may really be nothing more than a general indicator of optimism, in which case the Katona-Mueller procedure is the appropriate one. ${ }^{8}$

The second is the problem of weighting, both within and between the variables that constitute the index. A trichotomous $(2,1,0)$ scale for better-same-worse or up-no change-down supposes that the difference between better-worse is just twice as large as that between better-same or worse-same, and that households reporting "better" are distributed at the upper end of the true optimism scale in the same way as those reporting "same" are distributed in the middle part of the scale and those reporting "worse" at the lower end of the scale. Similar assumptions must hold for comparisons across the variables that are index components.

For the most part the CU data do not lend themselves to a thorough examination of this range of problems, since the surveys were not designed for exhaustive tests of this nature. However, enough information is available to explore the question of whether the relation between attitudes (or expectations) and subsequent purchases is suitably described by a trichotomous classification of the sort just discussed.

${ }^{7}$ The rationale for the procedure is described in Katona and Mueller, Consumer Expectations.

${ }^{8}$ In practice this difficulty only arises when both buying intentions and expectations are components of the index, since the possible negative association between expectations and purchases would be observed only when intentions are held constant. 


\section{EMPIRICAL RESULTS}

To examine the question of appropriate weighting I use responses to three variables that relate to household attitudes: ${ }^{9}$ These questions concern (1) actual change in family income over the past year; (2) expected change in family income during the next year; (3) expected change in general business conditions during the next year. All three questions were accompanied by a five-point scale: large increase (improvement), small increase (improvement), no change, and small or large decreases (deterioration). In addition, respondents could check categories labeled "don't know," "too uncertain to guess," or "other," depending on the particular question.

Alternative methods of scoring these responses were utilized. In the first, $1=$ increase (large or small) $2=$ no change, and $3=$ decrease (large or small); households with any other responses were excluded from the sample. Hence, the index scores range from a maximum of 9 (the most pessimistic group) to a minimum of 3 (the most optimistic group). For husband-wife households with heads between twenty-five and thirtyfour years of age, the weighted average number of durable goods purchased by each index score group is shown in Table 27.

This index, composed of three trichotomous classifications within each of three variables, has a highly significant relation to purchases. A oneway analysis of variance on the cell means yields an $F$ ratio of 3.49, significantly different from unity at the 0.01 level. The pattern of the cell averages is consistent-except for the group with an attitude score of 7with the proposition that favorable or optimistic attitudes are associated with relatively high purchases; pessimistic attitudes, with relatively low purchases. While it is true that those with optimistic attitudes tend to have relatively higher incomes than those with pessimistic attitudes, adjusting for the influence of family income weakens but does not alter the above relationship; differences in purchases among attitude classes are still significant at the 0.01 level, holding family income constant. The

\footnotetext{
${ }^{2}$ For present purposes I bypass two problems of considerable importance. First, are these questions really about attitudes, or about expectations, or about simple fact? Secondly, are these the appropriate questions to use in order to construct the best possible index of attitudes? Both are obviously significant questions. I put them aside now because the question of appropriate weighting is important regardless of whether the index really measures fact, diffuse attitudes, or expectations, and regardless of whether the best index should include more or different components. These particular questions happen to be available, and I do not claim that they constitute an optimal combination of variables that relate to (or measure) household optimism or pessimism.
} 
TABLE 27

Comparison of Three-Point Attitude Index Scores and Mean Durable Goods Purchases

\begin{tabular}{ccc}
\hline \hline Number of Households Score on Attitude Index \\
$(N)$ & $(A)$ & $\begin{array}{c}\text { Weighted Average } \\
\text { Number of Purchases } \\
(\widetilde{P})\end{array}$ \\
\hline 942 & 3 & 1.951 \\
1,191 & 4 & 1.827 \\
1,421 & 5 & 1.718 \\
830 & 6 & 1.582 \\
509 & 7 & 1.636 \\
138 & 8 & 1.536 \\
71 & 9 & 1.507 \\
5,102 & Total & 1.748 \\
\hline
\end{tabular}

SOURCE: Basic data from Consumer Purchase Study, NBER.

Note: $F=3.49$, significant at 0.01 level.

regression of the cell averages $(\bar{P})$ against the index scores $(A)$, weighting the averages by the number of cases in each cell, yields

$$
\bar{P}=2.175-0.087 A+u, r^{2}=0.0036
$$

(with the variance of $P$ taken as the actual variance for all 5,102 cases). There is no indication of nonlinearity in the pattern of residuals.

INDIGATIONS OF NONLINEARITY

Next I revised the scoring system to include the five-point scale for each of the three variables, counting large increase as 1 , small increase as 2 , no change as 3 , small decrease as 4 , and large decrease as 5 . By this count, scores will range from 3 (extreme optimism) to 15 (extreme pessimism). The distribution of households by attitude scores $\left(A^{\prime}\right)$, and mean purchases for each group, are shown in Table 28. Regressing purchases on these index scores,

$$
\widetilde{P}=2.439-0.086 A^{\prime}+u, r^{2}=0.0056
$$

Some of the results here are not very different from those obtained for the simpler classification; for example, the $F$ ratio for the cell means and the regression coefficient relating attitudes to purchases are about the same. $A^{\prime}$ explains more of the variance in $P$ than does $A$, but this is largely because the $A^{\prime}$ scale itself has substantially greater variance than the $A$ scale. However, the pattern of residuals in equation 2.0 clearly 
TABLE 28

Comparison of Five-Point Attitude Index Scores and Mean Durable Goods Purchases

Weighted Average

Number of Households Score on Attitude Index Number of Purchases $(N)$

$\left(A^{\prime}\right)$

$\begin{array}{rrr}2 & 3 & 4.000 \\ 48 & 4 & 2.542 \\ 253 & 5 & 2.217 \\ 924 & 6 & 1.887 \\ 1,130 & 7 & 1.762 \\ 1,162 & 8 & 1.669 \\ 764 & 9 & 1.569 \\ 489 & 10 & 1.744 \\ 192 & 11 & 1.526 \\ 88 & 12 & 1.511 \\ 22 & 13 & 1.545 \\ 17 & 14 & 1.118 \\ 6 & 15 & 0.667 \\ 5,102 & \text { Total } & 1.748\end{array}$

SOURCE: Basic data from Consumer Purchase Study, NBER.

Note: $F=3.95$, significant at 0.01 level.

shows that a linear regression is inappropriate. An $F$ test for nonlinearity indicates that the relation between $A^{\prime}$ and $\bar{P}$ is significantly nonlinear ( 0.05 level) even though all of the departures from linearity occur at the extremes, where the observations receive very little weight because the cell sizes are so small.

Partitioning of the sample by index score groups show the nonlinearity quite clearly. Linear regressions were calculated for the top four groups, the bottom four, and the five in the middle. The results are shown below (standard errors are in parentheses):

\begin{tabular}{|c|c|c|c|c|}
\hline & & Mean & $\begin{array}{l}\text { Regression } \\
\text { Coefficient of } \\
\overline{\bar{y}}\end{array}$ & \\
\hline $\begin{array}{l}A^{\prime} \text { Index Scores } \\
3,4,5,6\end{array}$ & $\begin{array}{c}N \\
1,232\end{array}$ & $\begin{array}{c}\text { Purchases } \\
1.993\end{array}$ & $\begin{array}{c}\bar{P}_{\text {on }} A^{\prime} \\
-.386(.107)\end{array}$ & $\begin{array}{c}r^{2} \\
.010\end{array}$ \\
\hline $7,8,9,10,11$ & 3,737 & 1.679 & $-.038(.030)$ & .0004 \\
\hline $12,13,14,15$ & 133 & 1.429 & $-.209(.166)$ & .012 \\
\hline All & 5,102 & 1.748 & $-.089(.016)$ & .006 \\
\hline
\end{tabular}

There is fairly conclusive evidence that only rather extreme expected or experienced changes are associated with subsequent differences in purchases of durables. Differences in the degree of optimism among a group that includes only fairly optimistic households are associated with large and statistically significant differences in purchases; that is, extreme optimists purchase substantially and significantly more than moderate 
optimists. The same is true of the association between differences in the degree of pessimism among pessimists and differences in purchases, although these differences are not statistically significant partly because the sample contains relatively few pessimistic households. On the other hand, equally wide (index score) differences in the degree of optimism or pessimism among those who are moderately one or the other (or completely neutral) are not associated with significant differences in purchases despite the very large sample of households in this category; for the moderate group, differences in purchases per scale unit are only. about onetenth as large as for either of the other two groups. Thus, all of the observed significant relationship between index scores and purchases is apparently due to the behavior of households at the extremes of the index score range.

SOME NONLINEAR FUNCTIONS

Further experiments involved fitting some nonlinear functions to these data. Nonlinear scores were introduced by assigning values of $1,4,5$, 6 , and 9 in place of the $1,2,3,4,5$ weighting underlying the Table 28 classification. The resulting scores range from 3 to 27 . I then estimated the three regressions shown below:

$$
\bar{P}=b_{0}+b_{1} T+u,
$$

where $T$ is the rescaled $A^{\prime}$ index.

$$
\bar{P}=b_{0}+b_{1} T^{\prime}+u,
$$

where $T^{\prime}=\left(\frac{1}{T}-\frac{1}{30-T}\right)$.

$$
\vec{P}=b_{0}+b_{1} T+b_{2} T^{2}+b_{3} T^{3}+u .
$$

Since equation 3.0 is simply a linear version of the nonlinear scale $(1,4,5,6,9)$ described above, it is a moderately nonlinear regression. Differences in behavior among those expecting or experiencing large changes, small changes, no change, etc., are presumed to be adequately reflected by the ratios of $1: 4: 5: 6: 9$; that is, those anticipating large increases are expected to show three times as much of a difference in purchases, relative to those anticipating small increases, as those anticipating small increases relative to those anticipating no change or no change relative to small decreases. Regressions 4.0 and 5.0 reflect the general relationship shown above - that the larger and more consistent are anti- 
cipated changes the greater will be the difference in purchases. Equation 4.0 imposes symmetry, in that the shape of the curve from 0 to 15 (the scale midpoint) must be a reversed (mirror) image of the shape in the 15-to-30 range; equation 4.0 also imposes a slope of infinity at scale values of 0 or 30 . Equation 5.0 does not contain any of these constraints; it could show that optimism and purchases are positively related in several segments of the scale and negatively related or unrelated elsewhere. The computed regressions, weighted by cell frequencies, are plotted in the top panel of Chart 13 and summarized below.

$$
\begin{aligned}
& 3.1 \vec{P}=2.608-0.0632 T+u, r^{2}=0.0067 \\
&(0.011) \\
& 4.1 \quad \bar{P}= 1.670+5.6467 T^{\prime}+u, r^{2}=0.0075 \\
&(0.910) \\
& 5.1 \quad \bar{P}=5.630-0.689 T+0.040 T^{2}-0.0008 T^{3}+u, R^{2}=0.0093 \\
&(0.191) \quad(0.013) \quad(0.0003)
\end{aligned}
$$

Unweighted regressions based entirely on the cell means, shown below, are plotted in the lower panel of Chart 13.

$$
\begin{array}{cc}
3.2 & \bar{P}=3.25-0.095 T+u, r^{2}=0.746 \\
& (0.012) \\
4.2 & \bar{P}=1.818+5.845 T^{\prime}+u, r^{2}=0.840 \\
& (0.557) \\
5.2 & \bar{P}=5.517-0.668+0.039 T^{2}-0.0008 T^{3}+u, R^{2}-0.850
\end{array}
$$$$
(0.330) \quad(0.024) \quad(0.0005)
$$

Chart 13 shows the computed regressions; the observed points are shown as heavy dots. The top panel (with the weighted regressions) shows the linear 3.1 equation and equation 4.1 plotted against the lower scale for attitude scores. The linear regression and equation 5.1 are plotted against the upper scale for attitude scores, and several of the observed points are redrawn as hollow dots. The two nonlinear functions are so close together in the middle range that it would be hard to tell them apart if both were shown on the same scale.

These results are quite interesting in several respects. First, both equations 4.1 and 5.1 constitute a significant improvement over equation 3.1 ; allowing for the loss of additional degrees of freedom, the $F$ ratio for the additional explained variance is significant $(0.05$ level $)$ for both weighted and unweighted versions of 4.0 and 5.0. Secondly, the differences between the weighted and unweighted regressions are rather striking. 
INFLUENCE OF ATTITUDES AND EXPECTATIONS

CHART 13

Regressions of Purchases

on Aftifude Index Scores
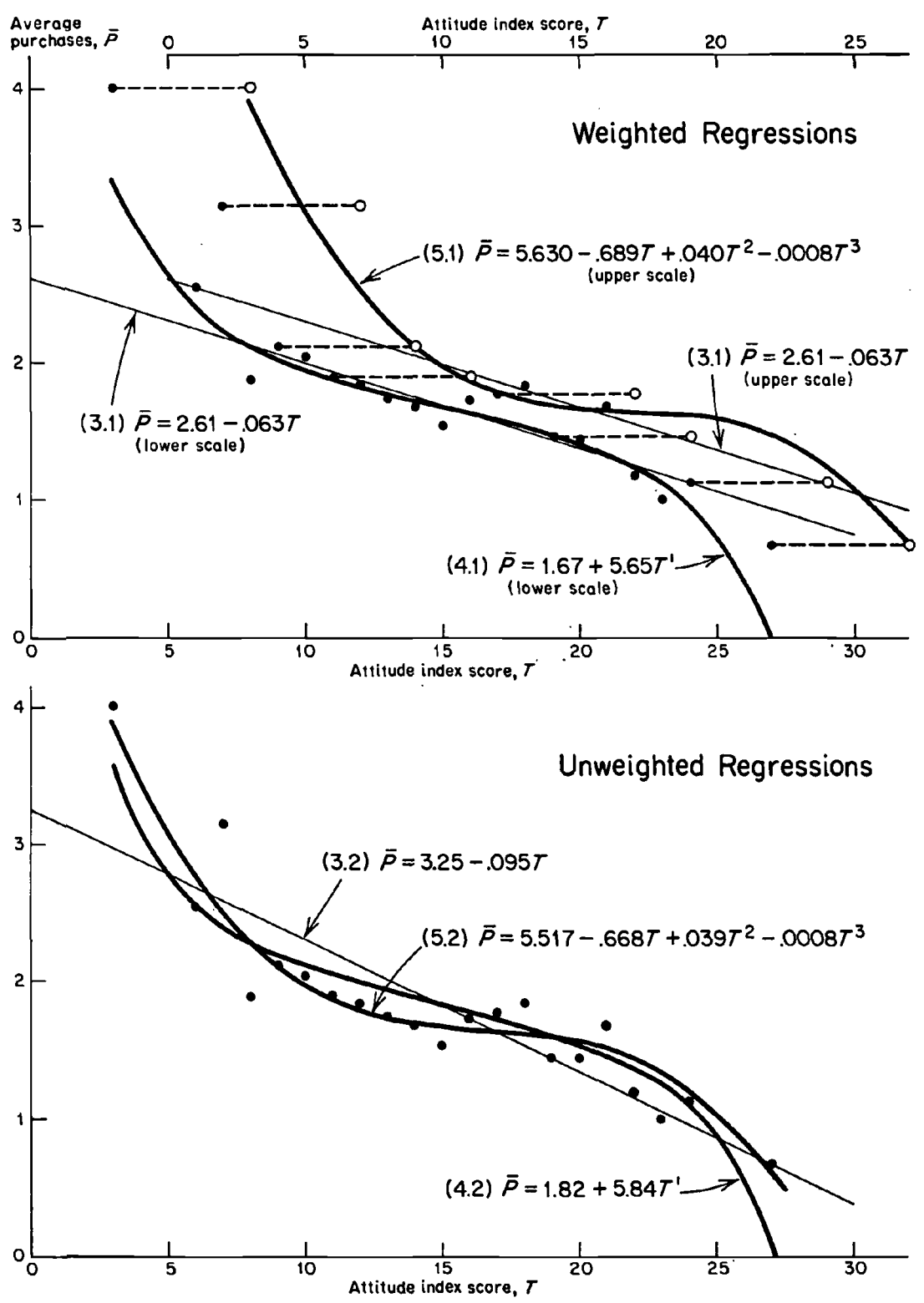
Regression 3.2 (unweighted) has a much larger (absolute) slope than 3.1 (weighted) because the extreme observations, which are well above the regression line at the optimism end of the scale and well below at the pessimism end, are given equal weight instead of a weight proportional to cell size. But the apparent fit of the 4.0 and 5.0 regressions is practically the same in both weighted and unweighted versions. Since the weights are arbitrary in the sense that they reflect the particular sample being surveyed, the unweighted regressions may be more meaningful as a measure of behavior for households with different characteristics provided that sampling errors in the cell means can be neglected. The fact that these regressions show the same results either weighted or unweighted indicates to me that they probably constitute a substantially accurate description of the true relationship between these variables.

Finally, equation 5.0 turns out to have a slope of close to zero in the middle range of attitude scores in both weighted and unweighted versions. As noted before, this regression is not constrained at all. But it is almost symmetrical about the scale midpoint, with a slope that indicates very little difference in purchases over the range of attitude scores from about 12 to 20 -out of a total range of scores from 3 to 27 . Both nonlinear functions have flatter slopes than the linear function in the middle of the scale, indicating that differences in moderate attitudes are not as useful in discriminating between households with relatively high or low purchase rates as are differences in extreme attitudes.

The above results suggest that differences in purchase behavior are dominated by the behavior of households expecting or experiencing large changes. Further tests of this hypothesis can be constructed. I divided the sample into the same number of groups as in the $A$ index (Table 27), but defined the groups on the assumption that expecting or experiencing large changes is the dominant cause of differences in purchases. Thus I lumped together all households that did not report any large actual or expected change on all three questions, and defined this group as having neutral attitudes. The remaining households were divided into three groups of optimists and three of pessimists, ${ }^{10}$ depending on the relative balance of optimistic and pessimistic replies on the three questions; the cell averages resulting from this classification $\left(A^{\prime \prime}\right)$ are shown in Table 29. The same tests were then run on this as on the Table 27 classification.

The classification in Table 29 is clearly superior to that in Table 27; the $F$ ratio is about twice as high, and the $A^{\prime \prime}$ index scores explain about

${ }^{10}$ A small residual group that had a pattern of optimism-pessimism-no change was also included in the neutral group. 
twice as much of the variance in $P$. The $A^{\prime \prime}$ classification is somewhat arbitrary; one can always improve (ex post) on a classification by rearranging households. Nonetheless, it is interesting to note the behavior of the "neutral" classification in Table 29. It comprises about three-quarters of all households in the sample, ranging all the way from those reporting

TABLE 29

Comparison of Nonlinear attitude Index Scores and Mean Durable Goods Purchases

\begin{tabular}{ccc}
\hline \hline $\begin{array}{c}\text { Number of Households Score on Attitude Index } \\
(N)\end{array}$ & $\begin{array}{c}\text { Weighted Average } \\
\text { Number of Purchases } \\
(\bar{P})\end{array}$ \\
\hline 84 & 3 & 2.880 \\
572 & 4 & 2.002 \\
231 & 5 & 1.922 \\
3,980 & 6 & 1.697 \\
74 & 7 & 1.635 \\
134 & 8 & 1.395 \\
27 & 9 & 1.000 \\
5,102 & Total & 1.748 \\
& & \\
\hline
\end{tabular}

Source: Basic data from Consumer Purchase Study, NBER.

NotE: The regression equation is

significant at 0.01 level.

$$
\begin{aligned}
& \bar{P}=2.912-0.202 A^{\prime \prime}+u, \\
& r^{2}=0.0074, \\
& F=7.7,
\end{aligned}
$$

a Scores 3 (9) are extreme optimism (pessimism), comprising at least two very optimistic (pessimistic) responses and a third of optimism (pessimism) or no change.

Scores 4 (8) are moderate optimism (pessimism), comprising one very optimistic (pessimistic) and one moderately optimistic (pessimistic) response; the third response must be neutral or optimistic (pessimistic). A few cases comprising two very optimistic (pessimistic) responses and a third of some degree of pessimism (optimism) were also included here.

Scores 5 (7) are slight optimism (pessimism), consisting of one very optimistic (pessimistic) response, one moderately optimistic (pessimistic) response, and a third of some degree of pessimism (optimism).

Score 6 is the neutral category, consisting of all households with no extremely optimistic or pessimistic response on any of the three questions. A few (173) cases that do not fit anywhere else are also included in this category.

actual or expected small increases to those reporting actual or expected decreases on all three questions. It cannot be shown that households in this group are significantly heterogeneous with respect to purchase behavior. This (neutral) $A^{\prime \prime}$ subgroup can itself be readily divided into seven subgroups, using the classification basis of Table 27. Analysis of variance on the cell means yields an $F$ ratio that is not significantly. different from unity despite a sample size of close to four thousand cases. 
GONGLUSIONS

On the whole, the evidence strongly suggests that extreme combinations of attitudes or expectations are significantly related to purchase behavior, while moderate ones are apparently either unrelated or quite weakly related. These relationships hold for a sample of relatively young families with the head of household between twenty-five and thirty-four years of age. It should be noted, however, that the same pattern was not found among older families with heads between forty-five and sixty-four. Here the data show that the relation between purchases and attitudes is relatively weak in general, although it is statistically significant for a linear classification like that in Table 28. Further, there is no evidence at all that a nonlinear classification such as $A^{\prime \prime}$ is an improvement. On the other hand, there is no indication that the neutral group in the $A^{\prime \prime}$ classification for these older families, comprising close to three thousand cases, is significantly heterogeneous, even though the range of (linear) attitude scores covers fully half the range of the entire classification. In sum, I would regard the evidence on the importance of extreme and the unimportance of moderate attitudes and expectations as strongly suggestive though not wholly conclusive.

\section{Purchases, Buying Intentions, and "Surprises"}

I turn now to the relation among expectations, outcomes, intentions, and purchases to find out whether surprises or whether expectations themselves seem to be associated with purchases net of intentions to buy. The relevant classifications can readily be constructed, since data are available on both expected and actual income change on a five-point scale ranging from large increase to large decrease. Thus, income surprise can be defined as actual change minus expected change $(\Delta Y-\Delta \bar{Y})$, where both $\Delta Y$ and $\Delta \hat{Y}$ range from 5 (large increase) to 1 (large decrease).

According to the contingent-action hypothesis, discussed earlier in this chapter, $\Delta Y-\Delta \hat{Y}$ should be positively correlated with purchases, holding buying intentions constant; groups of households with relatively large (algebraic) values of $\Delta Y-\Delta \hat{Y}$ should buy more, relative to intentions, than those with relatively small values of the surprise variable. As pointed out earlier, this measure of income surprise may be seriously deficient, because it depends wholly on a single-valued estimate of $\Delta \hat{Y}$ and does not take any account of dispersion. According to the additivity hypothesis, also discussed earlier, optimistic expectations should be associated with relatively heavy purchases net of buying intentions. 
Since increases in income would also tend to be associated with relatively heavy purchases, the additivity hypothesis can be interpreted as saying that $\Delta Y+\Delta \hat{Y}$ should be positively correlated with $P$ net of intentions because both components have a positive association. ${ }^{11}$

SOME PREVIOUS EVIDENCE RE-EXAMINED

Extensive tests of the relation between purchases $(P)$, buying intentions $(\hat{P})$, and expected and actual change in income $(\Delta \hat{Y}$ and $\Delta Y$, respectively) failed to uncover any systematic net relation between $P$ and the income expectation variable. Some of my investigations in earlier stages of this project $^{12}$ had indicated that, using grouped data, an equation of the form

$$
P / \hat{P}=b_{0}+b_{1} \Delta Y+b_{2} \Delta \hat{Y}+u
$$

yielded negative coefficients for $\Delta \hat{Y}$ and positive ones for $\Delta Y$ that were statistically significant. Thus, favorable income surprises appeared to be associated with high purchases relative to intentions, as predicted by the contingent-action hypothesis, while expectations themselves were associated with low purchases relative to intentions, contradicting the additivity hypothesis. The same paper also reported that an equation of the form

$$
P=b_{0}+b_{1} \hat{P}+b_{2} \Delta Y+b_{3} \Delta \hat{Y}+u
$$

yielded nonsignificant coefficients for both expected and actual change in income. The negative results of equation 6.1 were attributed to the differential impact of expected income change on purchases by intenders and nonintenders. The argument essentially is that expectations about income change may be acting as a probability-scaling device for those reporting zero buying intentions, while for those reporting nonzero intentions probability-scaling is dominated by the income-surprise role of income expectations. Hence, the net relation between purchases and expectations is positive for nonintenders, negative for intenders, and may not show up at all if both groups are averaged.

This explanation for the negative results of equation 6.1 may well be correct. However, the results of equation 6.0 clearly do not support the contingent-action hypothesis, since they are largely, if not entirely, due to a spurious correlation between expected change in income and the

11 Blending both hypotheses, one could argue that all three variables $-\Delta Y, \Delta \hat{Y}$, and $\Delta Y-\Delta \hat{Y}$-ought to have a positive association with purchases net of buying intentions. In this case the relation between $\Delta \hat{Y}$ and $P$ becomes impossible to predict, since it depends on whether the optimism or the surprise effect of $\Delta \vec{Y}$ predominates.

${ }^{12}$ See "Prediction and Consumer Buying Intentions," pp. 604-617. 
ratio of purchases to intentions. ${ }^{13}$ The spurious element in the correlation disappears if purchases and intentions are introduced as separate variables. ${ }^{14}$ Hence, the empirical tests that use group averages do not show any relation at all between the income change variables and purchases, net of buying intentions.

\section{SOME EXPERIMENTAL RESULTS}

The apparent lack of association between purchases and either expectations or surprises net of buying intentions is also shown by the results of an

$18 \mathrm{I}$ am indebted to George Katona for calling my attention to the spurious relation between income surprise and the ratio of aggregate purchases to aggregate intentions.

14 The explanation is as follows: We are interested only in whether households with pessimistic (optimistic) income expectations, holding income change constant, tend to buy more (less) relative to intentions than those with optimistic (pessimistic) expectations. If this turns out to be the case, it follows that agreeable or favorable surprises are positively correlated with purchases, given intentions. Let us take a group of households with varying expectations about income change, all of whom experienced no change in income. Some fraction of each income expectation class will report buying intentions for each of the commodities on the list, and another fraction will report that they have purchased; the dependent variable in equation 6.0 is the ratio of these two fractions, summed across commodities. That is,

$$
\begin{aligned}
P & =\Sigma x, \text { and } \\
\hat{P} & =\Sigma p ; \text { hence } \\
P / \hat{P} & =\Sigma x / \Sigma p .
\end{aligned}
$$

But it has been shown above that, using the notation of Chapters 2 and $3, x=$ $p r+(1-p) s ;$ hence

$$
P / \hat{P}=\frac{\Sigma[p r+(1-p) s]}{\Sigma p}=\frac{\Sigma p r}{\Sigma p}+\frac{\Sigma s(1-p)}{\Sigma p}
$$

Suppose, for the sake of argument, that income surprise is completely unrelated to behavior, i.e., that the contingent-action hypothesis has no empirical content. It follows that $r$ (the fraction of intenders who buy) and $s$ (the fraction of nonintenders who buy) will be the same for each of the income-surprise classifications; for if income surprise has no relation to behavior, it clearly will not influence either $r$ or $s$. But from the formulation above it is apparent that even if both $r$ and $s$ are invariant with respect to income surprise, $P / \hat{P}$ will be related to surprise provided that $p$ (the fraction of the group reporting intentions) happens to be related. It is known (empirically) that $p$ is correlated with income expectations; the more optimistic are expectations, the greater the fraction of households that report intentions. But holding actual change in income constant, expectations must be inversely correlated with income surprise; hence, a group of households with unfavorable income surprises (i.e., optimistic expectations) will have a higher value of $p$ than a group with favorable surprises (i.e., pessimistic expectations). The higher the value of $p$, holding $r$ and $s$ constant, the lower the ratio of $P$ to $\hat{P}$. As a consequence, households with unfavorable income surprises will show relatively low ratios of $P$ to $\hat{P}$ because of differences in $p$, even though $r$ and $s$ may be identical for all groups.

This spurious element is powerful enough to force a statistically significant negative correlation between $\Delta Y$ and $P / \hat{P}$. Suppose, for example, that $r=0.5$ and $s=0.2$, and that both $r$ and $s$ are the same for all commodities and also for optimists and pessimists. Suppose further that $p$ is 0.3 for optimists, 0.2 for pessimists. Then $P / \hat{P}$ for optimists is $0.5+[0.2(0.7 / 0.3)]=0.97$; for pessimists, $P / \hat{P}$ equals

$$
0.5+[0.2(0.8 / 0.2)]=1.30 \text {. }
$$


extensive multiple correlation analysis, using individual households as the unit of observation. The sample was stratified into relatively homogeneous life-cycle groups, since it seemed likely that these variables might have differential effects on behavior for young-old, married-unmarried, etc. The following regressions were computed for different life-cycle groups and for several of the intentions questions.

$$
\begin{array}{ll}
7.0 & P=b_{0}+b_{1} \hat{P}+b_{2} \Delta Y+b_{3} \Delta \hat{Y}+\cdots+u \\
8.0 & P=b_{0}+b_{1} \hat{P}+b_{2}(\Delta Y-\Delta \hat{Y})+\cdots+u \\
7.1 & P=b_{0}+b_{1} \hat{P}+b_{2} \Delta Y+b_{3} \Delta \hat{Y}+b_{4} Z \Delta \hat{Y}+\cdots+u \\
8.1 & P+b_{0}+b_{1} \hat{P}+b_{2}(\Delta Y-\Delta \hat{Y})+b_{3} Z(\Delta Y-\Delta \hat{Y})+\cdots+u
\end{array}
$$

In 7.1 and $8.1, Z=1$ when $\hat{P}=0$; otherwise $Z=0$.

On the whole, the results were discouraging. Significant positive coefficients for income surprise or significant negative coefficients for income expectations appeared on occasion; but so did significant coeffcients with the opposite sign; and the bulk of the $\Delta \hat{Y}$ and $\Delta Y-\Delta \hat{Y}$ coefficients were nonsignificant despite sample sizes of typically over seven hundred cases. If any systematic pattern was present in these coefficients, it was not readily apparent.

The lack of positive results could be due to several factors. First, either expectations, or surprises, or both may in fact be unrelated to behavior. Secondly, a relation between expectations and purchases may actually exist but cannot be observed unless a good measure of the dispersion of expectations can be included in the analysis; as pointed out before, my data do not have such a measure. Finally, it is possible that the relation among expectations, outcomes, purchases, and buying intentions depends on the level of purchase probability associated with intentions.

As regards the second point, correspondence between analytical concepts and the survey variables used to represent them is not necessarily close. For example, we speak of testing to determine whether or not subjectively held expectations about income are related to purchase behavior. But we are not really testing income expectations per se; rather, the test variable consists of responses to a particular question bearing on income prospects. If the empirical results indicate that subjective income expectations are unrelated to purchases, it may mean only that the particular question is an unsatisfactory representation of expectations. Income expectations (properly measured) undoubtedly have a bearing on decisions to buy durable goods, although subjective statements concerning income prospects may not be useful. 
In a way, empirical analysis of survey data is an attempt to find particular questions that are capable of being used as proxies for analytically relevant variables. In some cases it is known from theory that a factor is related to behavior in a particular way, and it is required to find out if the relationship is strong or weak, or whether it has the same influence in all groups. If survey responses that purport to represent this factor are tested and no relationship is found, the presumption is that the particular question is poorly suited. In other cases it may not be known whether the measuring rod is faulty or whether there simply is no important behavioral relationship present.

As regards the third point, let us now take a closer look at the relation between purchases, intentions to buy, and deviations between expected and actual income changes (surprises). It was argued above that those with favorable or agreeable surprises ought to purchase more, relative to intentions, than those with no surprises; by the same token, those with unfavorable or disagreeable surprises ought to purchase less, relative to intentions, than those with no surprises. The empirical evidence did not support the existence of such a relation, either because the relation in fact does not exist or because the measure of surprise is deficient.

But it can also be plausibly argued that these relations depend on the specification of a "buying intention," in particular, on the purchase probability associated with a statement of intention to buy. Suppose that two kinds of intentions are reported by households-those with a very high purchase probability and those with a probability that is relatively low but significantly higher than zero. Let us designate highprobability buying intentions as "standard" $(\hat{P})$, low-probability intentions as "contingent" $\left(\hat{P}_{c}\right) .^{15}$ It could be argued that favorable surprises will have comparatively little influence on the ex post probability of purchase by households with standard $(\hat{P})$ intentions because $e x$ ante purchase probability is already very high; ${ }^{16}$ unfavorable surprises, on the other hand, might have a relatively strong effect on ex post purchase probability for these households. High ex ante purchase probability must have been predicated on a set of expectations, at least one of which (income expecta-

${ }^{15}$ The designation is the same as that used in Chapter 5 for a similar purpose.

${ }^{16} \mathrm{By}$ ex ante purchase probability I have in mind the respondent's subjective purchase probability as of the survey date; by ex post purchase probability, his subjective probability as of the survey date if he had known with certainty the actual course of external events during the forecast period. Thus, ex ante and ex post purchase probability are the same for a respondent with perfectly certain expectations about external events all of which occur. Ex ante probability is greater than ex post probability for a respondent who experiences unfavorable (and unforeseen) changes; and the reverse is true for a respondent who experiences favorable (and unforeseen) changes during the forecast period. 
tions) has resulted in disappointment for the group experiencing unfavorable or disagreeable surprises. As a consequence, some households in this group may be unable or unwilling to purchase in accordance with their ex ante probabilities.

A similar dichotomy may be present with respect to the relation among purchases, contingent intentions $\left(\hat{P}_{c}\right)$, and surprises. Favorable surprises would be expected to have an especially strong influence on the purchases of households with contingent intentions, since the intentions themselves may have been contingent (ex ante) precisely because income had not been expected to change in as favorable a way as it actually did. On the other hand, the groups with no surprises or with unfavorable ones might be expected to show the normally weak relation between $P$ and $\hat{P}_{c}$; since the relation is weak to begin with, those with unfavorable surprises may act in much the same way as those with no surprises.

In sum, the association between purchases and standard intentions may be significantly weaker for the unfavorably surprised than for others, and may be somewhat stronger for the favorably surprised than for the no-surprise group. 'The relation between purchases and contingent intentions may be especially strong for the favorably surprised, perhaps somewhat weaker for the unfavorably surprised than for the no-surprise group.

It must be remembered that these analytical concepts are very imperfectly represented by the data. In particular, lacking a measure of the dispersion of expectations, the surprise variable is suspect. As noted before, mean expected change, which is to be compared with reported change, is hardly an adequate description of expectations. Further, a clean distinction between standard and contingent plans, as these terms are used above, is lacking.

As a first step, I separated out households with agreeable or disagreeable income surprises and estimated regression coefficients for purchases on standard and contingent intentions. The results were more consistent than those found in previous tests, but the differences were rather small and hardly ever significant. Next, I adopted a more rigorous definition of surprise, requiring that households report unexpectedly favorable or unfavorable developments with respect to both income and general business conditions. The rationale is simply that one can be more confident that a given household actually received a pleasant surprise if it received more income than its (mean) expectation and also thought that business conditions had developed more favorably than anticipated at the survey date. Similarly, I felt more confident that a given household had been unpleasantly surprised if it received less income than expected and also 
thought that business conditions had developed less favorably than anticipated.

This redefinition of income surprise, and the hypotheses discussed above, were tested on two of the variant groups-the A sample, where $\hat{P}$ represents definite intentions to buy within a year and $\hat{P}_{c}$, probable-possible intentions to buy within a year; and the $\mathrm{C}$ sample, where $\hat{P}$ represents intentions to buy within a year, and $\hat{P}_{c}$ intentions to buy within a year if income were to be 10 to 15 per cent higher than expected. At first glance it looks as if the intentions questions asked of the $\mathrm{C}$ sample are ideally suited for this test because one of the intentions questions is specifically contingent on unexpectedly favorable income developments. However, the analysis suggests that the dichotomy between purchases and the effect of surprises for those with standard or contingent intentions should be most evident when $\hat{P}$ includes only those intentions with very high purchase probabilities and $\hat{P}_{c}$ includes only intentions with probabilities significantly higher than zero and lower than $\hat{P}$. As I have shown in Chapter 3 , the purchase probabilities associated with $\hat{P}$ and $\hat{P}_{\mathrm{c}}$ for the A group come much closer to this analytical definition than do the probabilities associated with $\hat{P}$ and $\hat{P}_{c}$ for the $\mathrm{C}$ group.

Table 30 summarizes correlations for husband-wife households with the head between twenty-five and thirty-four years of age. The top panel shows simple correlation and regression coefficients for the A and C samples and for the two samples combined. The middle panel has coefficients for a multiple regression in which $\hat{P}$ and $\hat{P}_{c}$ are assumed to be linearly related to $P$. Results of a multiple regression that allows for interaction between $\hat{P}$ and $\hat{P}_{c}$ (along the lines discussed in Chapter 5) are summarized in the bottom panel.

The data in Table 30 are rather encouraging, considering the hodgepodge of coefficients in the regression analysis described earlier. The linear multiple regressions are apt to be the most reliable, since the interaction term in the bottom panel tends to make the regression coefficients quite sensitive to sampling variations; because of the way in which surprise is defined, both the favorably surprised group (F) and the unfavorably surprised group (U) are quite small. The A sample shows results that are almost wholly in accord with the proposition that $\hat{P}$ is less closely associated with $P$ for those with unfavorable surprises than for either of the other two groups, and that $\hat{P}_{c}$ is more closely associated with $P$ for those with favorable surprises than for either of the other groups. The net regression coefficient of $\hat{P}$ in the two lower panels is substantially lower for the U group than for either of the other two groups; the differences are 
significant $(0.05$ level) for the linear multiple regression but not for the regression with interaction. The $\hat{P}$ coefficient is also higher for $\mathrm{F}$ than $\mathrm{N}$ in both panels, though the differences are relatively small and not statistically significant. The $\hat{P}_{c}$ coefficients behave equally well, being highest for the $F$ group and lowest for the $U$ group in both panels. All of the

TABLE 30

Effect of Income SuRprise on Relation Between Purchases and Intentions

\begin{tabular}{|c|c|c|c|c|c|c|c|c|c|}
\hline & $A S a$ & mple Subg & & $4 \Delta a$ & nole Dougt & & $A+C$ & Sample $S u$ & bgroups \\
\hline & $F(84)$ & $N(718)$ & $\mathrm{U}(50)$ & $F(68)$ & $N(682)$ & $\mathrm{U}(64)$ & $F(152)$ & $N(1400)$ & U (114) \\
\hline & & & & APLE COR & EELATIONS & & & & \\
\hline $\begin{array}{l}b_{13} \\
r^{2} 12 \\
b_{13} \\
r^{2} 13\end{array}$ & $\begin{array}{c}+.539^{\mathrm{a}} \\
.130 \\
+.228^{\mathrm{b}} \\
.048\end{array}$ & $\begin{array}{c}+.396^{\mathrm{a}} \\
.092 \\
+.083^{\mathrm{a}} \\
.010\end{array}$ & $\begin{array}{r}+.077 \\
.003 \\
-.010 \\
.000\end{array}$ & $\begin{array}{r}+.289^{b} \\
.085 \\
+.066 \\
.009\end{array}$ & $\begin{array}{r}+.384^{\mathrm{a}} \\
.146 \\
+.043 \\
.002\end{array}$ & $\begin{array}{r}+.353^{\mathrm{a}} \\
.164 \\
+.089 \\
.013\end{array}$ & $\begin{array}{r}+.358^{a} \\
.084 \\
+.127 \\
.021\end{array}$ & $\begin{array}{c}+.368^{\mathrm{a}} \\
.118 \\
+.066^{\mathrm{a}} \\
.005\end{array}$ & $\begin{array}{r}+.254^{\mathrm{B}} \\
.071 \\
+.051 \\
.004\end{array}$ \\
\hline & & & & TIPLE CO & RRELATIOI & & & & \\
\hline $\begin{array}{l}b_{12.3} \\
b_{13.2} \\
R^{2}{ }_{1.23}\end{array}$ & $\begin{array}{r}+.564^{\mathrm{a}} \\
+.255^{\mathrm{b}} \\
.190\end{array}$ & $\begin{array}{c}+.402^{\mathrm{a}} \\
+.094^{\mathrm{a}} \\
.104\end{array}$ & $\begin{array}{r}+.093 \\
-.031 \\
.005\end{array}$ & $\begin{array}{r}+.308^{b} \\
+.095 \\
.104\end{array}$ & $\begin{array}{c}+.394^{\mathrm{a}} \\
+.082^{\mathrm{b}} \\
.153\end{array}$ & $\begin{array}{r}+.349^{\mathrm{a}} \\
+.074 \\
.173\end{array}$ & $\begin{array}{c}+.373^{\mathrm{a}} \\
+.147^{\mathrm{b}} \\
.112\end{array}$ & $\begin{array}{c}+.374^{\mathrm{a}} \\
+.086^{\mathrm{a}} \\
.127\end{array}$ & $\begin{array}{r}+.251^{\mathrm{a}} \\
+.019 \\
.072\end{array}$ \\
\hline & & & 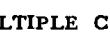 & FT & WITH I & NTERAC & & & \\
\hline $\begin{array}{l}b_{12.34} \\
b_{13.24} \\
b_{14.23} \\
R_{1.234}^{2}\end{array}$ & $\begin{array}{c}+.634^{\mathrm{a}} \\
+.282^{\mathrm{b}} \\
-.046 \\
.192\end{array}$ & $\begin{array}{c}+.561^{\mathrm{a}} \\
+.150^{\mathrm{a}} \\
-.092^{\mathrm{a}} \\
.120\end{array}$ & $\begin{array}{r}+.341 \\
+.055 \\
-.093 \\
.014\end{array}$ & $\begin{array}{r}+.273^{b} \\
+.072 \\
+.019 \\
.105\end{array}$ & $\begin{array}{c}+.460^{\mathrm{a}} \\
+.135^{\mathrm{a}} \\
-.034 \\
.157\end{array}$ & $\begin{array}{c}+.384^{\mathrm{a}} \\
+.105 \\
-.020 \\
.174\end{array}$ & $\begin{array}{c}+.414^{\mathrm{a}} \\
+.169^{\mathrm{b}} \\
-.025 \\
.114\end{array}$ & $\begin{array}{c}+.469^{\mathrm{a}} \\
+.139^{\mathrm{a}} \\
-.052^{\mathrm{a}} \\
.134\end{array}$ & $\begin{array}{l}+.308^{\mathrm{a}} \\
+.061 \\
-.030 \\
.074\end{array}$ \\
\hline
\end{tabular}

SourCE: Basic data from Consumer Purchase Study, NBER.

Note: The data cover husband-wife households with head of house between twentyfive and thirty-four years old. F represents the group of households experiencing favorable income surprise; $N$, no surprise; $U$, unfavorable surprise (see accompanying text for definition of income surprise). The sample size for each group is given in parentheses beside the symbol. A and $\mathrm{C}$ refer to buying intentions questions (see text). The variables are as follows:

$$
\begin{aligned}
& X_{1}=P=\text { purchases } \\
& X_{2}=\hat{P}=\text { standard intentions } \\
& X_{8}=\hat{P}_{c}=\text { contingent intentions } \\
& X_{4}=\hat{P} \hat{P}_{c}=\text { interaction of standard and contingent intentions }
\end{aligned}
$$

a Significantly different from zero at 0.01 level, using $t$ test.

b Significantly different from zero at 0.05 level, using $t$ test.

differences in the middle panel are statistically significant; the $\hat{P}_{c}$ coefficient for the $U$ group is significantly smaller than that for the other two groups in the lowest panel.

On the other hand, none of these generalizations holds for the $\mathrm{C}$ group. Here there are no significant differences among the $\hat{P}$ or $\hat{P}_{c}$ coefficients in any of the three groups, perhaps because the $\hat{P}$ variant in the $\mathrm{C}$ group is clearly not limited to high-probability buying intentions. In fact, the $\hat{P}$ 
variable for group $\mathrm{C}$ is not very different from the algebraic sum of $\hat{P}$ and $\hat{P}_{c}$ in group $\mathrm{A}$, judging from data in Chapter 2 .

When the two groups are combined, the pattern shown by the A group is somewhat diluted but still clearly apparent. The reliability of the combined results is greater because the sample sizes for the $F$ and $U$ groups are about twice as large as before; but the reliability is presumably reduced by the difference in the meaning of standard and contingent intentions in the two groups. In the bottom panel the U group has a lower $\hat{P}$ coefficient than either $\mathrm{F}$ or $\mathrm{N}$, and the $\hat{P}$ coefficient is not significantly different for $\mathrm{F}$ and $\mathrm{N}$. The $\mathrm{F}$ group has the highest $\hat{P}_{c}$ coefficient; the $\mathrm{U}$ group, the lowest.

An interesting sidelight on these results is the behavior of the interaction variable. Interaction between standard and contingent intentions appears to be stronger for households in the $\mathrm{N}$ group than for households in either of the groups experiencing surprises. This fact makes little difference for comparisons involving the $U$ group, but it widens the difference between the $\hat{P}_{c}$ coefficients for the $\mathrm{F}$ and $\mathrm{N}$ groups whenever $\hat{P}$ takes on values greater than zero. The tabulation below illustrates the behavior of the $\hat{P}_{c}$ coefficients for the $\mathrm{F}$ and $\mathrm{N}$ groups, taking account of the interaction between this variable and $\hat{P}$. Data are shown for the A group and for the combined $\mathrm{A}$ and $\mathrm{C}$ groups.

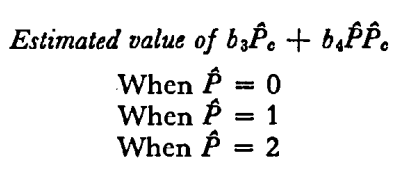

\begin{tabular}{cccc}
\multicolumn{2}{c}{ A Sample } & \multicolumn{2}{c}{$A+C$ Samples } \\
$\mathbf{F}$ & $\mathbf{N}$ & $\mathbf{F}$ & $\mathbf{N}$ \\
+.282 & +.150 & +.169 & +.139 \\
+.236 & +.058 & +.144 & +.087 \\
+.190 & -.034 & +.119 & +.035
\end{tabular}

As can be seen, the estimated net influence of contingent intentions on purchases for the $\mathrm{N}$ group moves rapidly to zero as standard intentions increase, but continues to be strongly positive for the $\mathrm{F}$ group. It thus seems to be the case that the differential influence of $\hat{P}_{c}$ on $P$, as a function of the level of $\hat{P}$, is less important in the $\mathrm{F}$ group. Since this group starts out with a higher $\hat{P}_{c}$ coefficient when $\hat{P}_{\text {is }}$ zero, it appears that $\hat{P}_{c}$ is always more important in the $\mathrm{F}$ than in the $\mathrm{N}$ group, but the differential is wider when $\hat{P}$ has relatively large values.

The last test relating to this problem involves estimating coefficients for a multiple regression designed as a more general test of the proposition that $\hat{P}$ (for the $\mathrm{U}$ group) and $\hat{P}_{c}$ (for the $\mathrm{F}$ group) have special significance relative to the $\mathrm{N}$ group. The regression has the form

$$
P=b_{0}+b_{1} \hat{P}+b_{2} \hat{P}_{c}+b_{3} Z \hat{P}+b_{4} Z_{1} \hat{P}_{c}+u
$$


where $P=$ purchases of durables

$\hat{P}=$ standard intentions to buy durables

$\hat{P}_{c}=$ contingent intentions to buy durables

$Z \hat{P}=$ standard intentions to buy durables

$Z=1$ for $\mathrm{U}$ households and 0 for all other households

$Z_{1} \hat{P}_{c}=$ contingent intentions to buy durables

$Z_{1}=1$ for $\mathrm{F}$ households and 0 for all other households

TABLE 31

Differential Importance of Income Surprise on the Relation Between, INTENTIONS AND PURGHASES

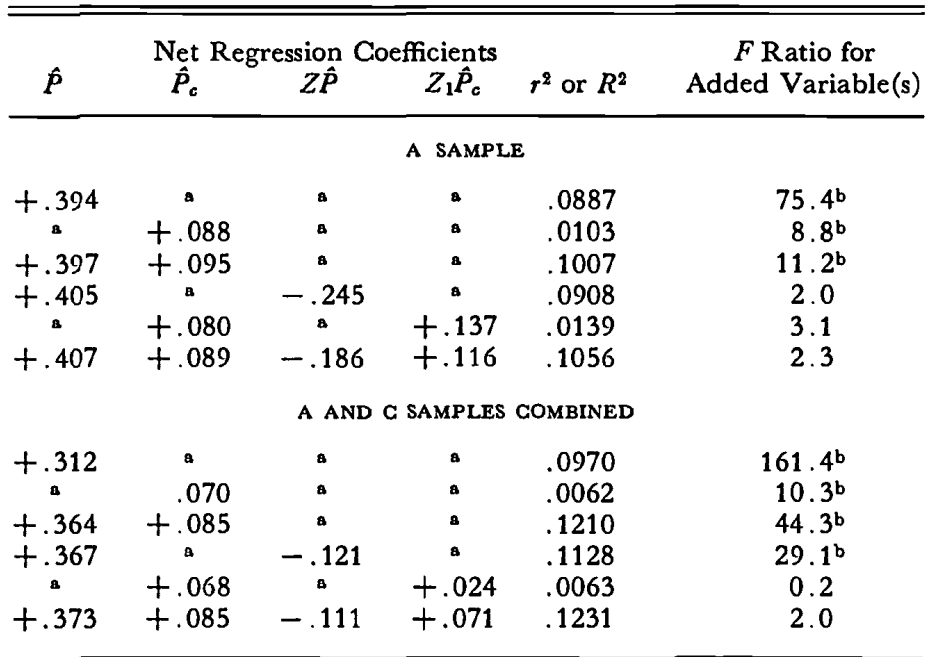

Source: Basic data from Consumer Purchase Study, NBER.

Note: For the A sample, $N=852$; for the $\mathrm{A}$ and $\mathrm{C}$ samples combined, $N=1,666$. See accompanying text for explanation of table.

a Variable excluded from regression.

b Significantly different from unity at 0.01 level.

If the standard intentions of unfavorably surprised households are less closely associated with purchases than is the case for other households, $b_{3}$. should be less than zero. Similarly, if the contingent intentions of favorably surprised households are more closely associated with purchases than is the case for other households, $b_{4}$ should be greater than zero. Both $b_{1}$ and $b_{2}$ should be greater than zero, since both standard and contingent buying intentions are expected to be positively associated with purchases even if any special influences of $\hat{P}$ for the $\mathrm{U}$ group and $\hat{P}_{c}$ for the F group are held constant. The data are summarized in Table 31, with regressions shown for different clusters of variables.

The signs of all regression coefficients are in accord with the propositions 
advanced above, although the $Z$ and $Z_{1}$ terms generally do not make a statistically significant contribution to explained variance. The most appropriate test of the two interaction variables consists of comparing the results for the last equation in each panel with those for the third. The difference between these two equations is that both interaction variables have been added to a regression including $\hat{P}$ and $\hat{P}_{c}$; in neither panel does the combined influence of the additional variables add significantly to the explanation of purchases. On the other hand, $Z \hat{P}$ makes a significant contribution to the explanation of $P$ in the lower panel (compare the first and fourth equations), and some of the other variables involving $Z$ or $Z_{1}$ are significant at the 0.10 level, though not at $0.05 .{ }^{17}$

Tests similar to those summarized in Table 31 were run on different subgroups with results that were not as consistent. In other subsamples one of the interactions generally had the expected sign while the other behaved erratically. For example, in the subsample composed of husband-wife households with the head between thirty-five and forty-four years old, the $U$ group had a smaller coefficient for standard intentions than either the $\mathrm{F}$ or $\mathrm{N}$ group, as predicted. But this same group also had a larger coefficient for contingent intentions than either the $\mathrm{F}$ or $\mathrm{N}$ group, which makes no particular sense. The contingent-plan coefficient for $\mathrm{F}$ was in turn higher than that for $\mathrm{N}$, in accordance with expectations. None of the differences in regression coefficients were large enough to be statistically significant.

\section{Summary}

The results of this investigation into the relation among durable goods purchases, buying intentions, expectations, and/or surprises can best be categorized as suggestive of possible relationships but inconclusive as to whether expectations and/or surprises are actually related to purchases net of buying intentions. A nonlinear relation between expectations and purchases seems quite probable, because extremely optimistic (pessimistic) expectations are associated with relatively high (low) purchases, while moderate optimism (pessimism) appears to be unrelated to purchases. Whether this relation continues to exist net of buying intentions has not been examined above, but evidence to be presented later suggests that

17 These interaction terms do not show significance partly because each is relevant for only a small proportion of the total cases and, hence, each makes a relatively small contribution to total explained variance for all cases taken together. This seems to be the reason why the $Z \hat{P}$ term in the top panel increases explained variance by a trifling amount (compare the first and fourth equations) despite its very large absolute size. The $Z \hat{P}$ term is relevant in only 50 (of 852 ) cases. Although these cases fit considerably better when $Z \hat{P}$ is included along with $\hat{P}$, the remaining cases are affected only very slightly. The net improvement is not statistically significant. 
some net relation between a nonlinear index of expectations and purchases may well be present. Still, even the best fit obtained (between purchases and a cubic equation involving expectations) was able to explain less than 1 per cent of the variance in purchases. This performance stands in sharp contrast to the 10 to 20 per cent of the variance in purchases typically explained by intentions to buy.

Similarly, I was unable to find any simple relation between surprises and purchases net of buying intentions. Experiments with a more stringent definition of favorable and unfavorable surprise suggested the possibility that favorable surprises, in interaction with contingent buying intentions, may be positively related to purchases; unfavorable surprises in interaction with standard buying intentions may be negatively related to purchases. The evidence in support of these propositions is a long way from being convincing. While the data generally yield regression coefficients with the appropriate signs, many of the coefficients are not significantly different from zero; the contribution to explained variance is generally very small; and in some cases, the data yield coefficients with inappropriate signs. Still, the results are sufficiently promising to suggest that these relations are worth further investigation and are potentially valuable in explaining consumer behavior.

Finally, the results in this chapter suggest that only rather large deviations from average experience are of much value in explaining the relation of expectations and/or surprises to purchase behavior. In effect, these results seem to indicate that households with very optimistic expectations or very favorable surprises are likely to buy considerably more durable goods, other things being equal; those with very pessimistic expectations or very unfavorable surprises, considerably fewer. These extreme cases are of little quantitative importance to the sort of data. I have been using. The vast bulk of households in a cross section do not fall into either of these categories, and the evidence suggests that the necessarily modest differences in expectations or surprises among households in the middle group are not related to differences in behavior. But it does not follow that these variables play an equally minor role in the explanation of differences in purchase behavior over time. Although only a small (absolute) number of households experience either extreme expectations or surprises during any one period, the time series variance in the number of such households is likely to be considerable. This fact, coupled with the possibility of a quantitatively important association between extreme expectations or surprises and purchases, may mean that an important part of the time series variation in purchases is associated with changes in the proportion or number of households in these extreme categories. 